\title{
Research on Fault Diagnosis Method of Diesel Engine Thermal Power Conversion Process
}

\author{
Kun Yang ${ }^{1, a}$, Huanyu Fan ${ }^{1, b}$ \\ 1College of Power Engineering, Naval University of Engineering, Wuhan, China \\ aemail:150006224@qq.com,,email:89389123@qq.com
}

\begin{abstract}
Keywords: Thermal power conversion, AVL BOOST, Fault sign, Thermal parameter sensitivity, Fault diagnosis system.

Abstract: In order to solve the problem that the fault samples are too few in the fault diagnosis of a certain type of diesel engine, a diagnostic method based on the simulation of fault symptoms was proposed. First of all, used AVL BOOST software to simulate the working process of diesel engine, extracted the fault sensitivity of thermal parameters. The failure symptom set of the model diesel engine was established based on the simulation results, and designed the diesel engine fault diagnosis system based on symptom set. Verified the reliability of the model and the feasibility of this method by fault experiment, the experimental results showed that the method was feasible.
\end{abstract}

\section{Introduction}

Diesel engine operation process contains many links, the thermal power conversion process is the most critical and the most complex link. The whole process time is short and not continuous, the diagnosis is difficult. The main reason for the failure of the thermal power conversion is the reduction of cylinder inflation, the organized abnormally of the burning process and the mechanical loss increased etc. The commonly used fault diagnosis method is the thermal parameter method. Thermal parameters include dynamometer, speed, fuel consumption, exhaust temperature etc., the values of these thermodynamic parameters reflect the state of the thermal transfer process in different degrees. For diesel engine fault diagnosis, faulty samples is required. And for a certain model to determine the diesel engine, fault samples to obtain more difficult. And for a certain type of diesel engine, fault samples is difficulty to obtain. For this problem, we established a mathematical model for thermal power conversion process, calculated the thermal parameters. Set fault to measure the thermal parameters, diagnosed the fault of thermal power conversion process by comparing the measured and simulated data, got a feasible fault diagnosis method.

\section{Mathematical model and basic assumptions of cylinder working process}

The combustion chamber usually refers to the space formed by the cylinder head, the inner wall of the cylinder liner and the piston top. Fresh charge through the intake pipe into the cylinder, the exhaust gas from the cylinder into the exhaust pipe, the cylinder and the outside world for quality exchange, the power and heat are exchanged with the outlet in compression and expansion process.

According to the conservation of energy, the principle of conservation of quality, zero-dimensional model was used to calculate the thermodynamic parameters of each moment. The following simplified assumptions were made when deriving the basic differential equation of the cylinder process calculation:

1) The working fluid state is uniform, the pressure, temperature and concentration of the points in the same instantaneous cylinder are equal. During the intake period, the fresh charge into the 
cylinder is completely fused to the moment in the cylinder; when the fuel is sprayed, the fuel is completely mixed with the in-cylinder gas.

2) The working fluid is the ideal gas. Specific heat capacity, Internal energy, Enthalpy etc. related the gas temperature and gas composition only.

3 ) The flow of gas into or out of the cylinder is a quasi-stable flow process.

4) The kinetic energy of the import and export of working fluid is negligible

\section{Analysis of Thermal Power Failure Simulation.}

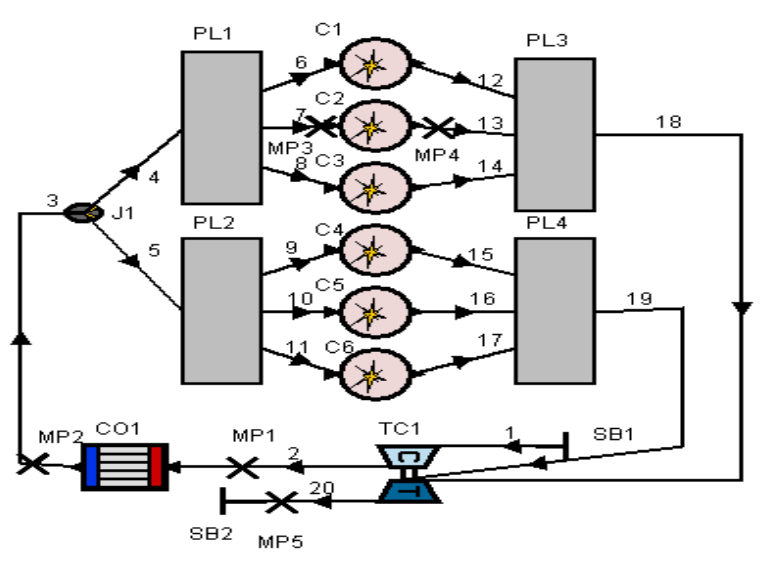

Figure 1. Simulation model
The research object was TBD234V6 turbocharged diesel engine. Diesel engine work process simulation software (AVL BOOST) was used to build its work process simulation model. Several thermal conversion failure was simulated and analyzed with this model.

We simulated several common TBD234V6 diesel engine faults, under the speed of $1500 \mathrm{r} / \mathrm{min}, 1800 \mathrm{r} / \mathrm{min} 2100 \mathrm{r} / \mathrm{min}$. The thermal power failure and fault setting method were shown in Table 1.

Table 1. Thermal power conversion process fault setting table

\begin{tabular}{|c|c|c|}
\hline Fault classification & Fault name & Set method \\
\hline \multirow{4}{*}{$\begin{array}{c}\text { Cylinder thermal } \\
\text { failure }\end{array}$} & Oil spill failure & Adjust the circulating fuel injection \\
\cline { 2 - 3 } & Poorly sprayed atomization & Adjust the quality of combustion \\
\cline { 2 - 3 } & Fuel injection failure & Adjust the fuel injection time \\
\cline { 2 - 3 } & Compression failure & Adjust the cylinder compression ratio \\
\cline { 2 - 3 } & Exhaust valve failure & Adjust the effective circulation area calibration factor \\
\hline \multirow{5}{*}{$\begin{array}{l}\text { Peripheral system } \\
\text { failure }\end{array}$} & Valve timing fault & Adjust the exhaust valve to turn off the timing angle \\
\cline { 2 - 3 } & Turbocharger failure & Adjust the total efficiency of the turbocharger \\
\cline { 2 - 3 } & Intercooler air side fouling & Adjust the pressure loss on the side of the intercooler \\
\cline { 2 - 3 } & Intercooler efficiency failure & Adjust the intercooler efficiency \\
\cline { 2 - 3 } & Exhaust manifold fouling & Adjust the cylinder exhaust manifold diameter \\
\cline { 2 - 3 } & Lubrication system failure & Adjust the average effective pressure of friction \\
\cline { 2 - 3 } & Crankcase blowout failure & Adjust the blower gap \\
\cline { 2 - 3 } & Turbine exhaust pipe fouling & Adjust the turbine exhaust manifold diameter \\
\cline { 2 - 3 } & Exhaust gas turbine flows to fouling & Adjust the total pipe friction coefficient \\
\hline
\end{tabular}

In this paper, a total of 7 single-cylinder thermal performance parameters and 3 machine thermal performance parameters were extracted, a total of 15 thermodynamic performance parameters were used as the simulation results and the fault analysis was carried out by using these parameters. They were : indicating efficiency $\eta_{i}$, effective fuel consumption rate $g_{g}$, average effective pressure $P_{\theta}$, Effective power $N_{g}$,cylinder maximum combustion pressure $P_{\mathbb{Z}}$, the maximum combustion 
temperature $T_{E}$, the front and back pressure of the intercooler $P a_{i n}$ and $P a_{\text {out }}$, the front and back temperature of the intercooler $T a_{i n}$ and $T a_{\text {out }}$, exhaust gas turbine outlet temperature $T t_{\text {out }}$, gas pressure and gas temperature of intake and exhaust manifold $P c_{i n}, P c_{\text {vat }}, T c_{i n}, T c_{\text {out }}$.

Defined a parameter $\delta$ as the deviation between the thermal performance parameters of the diesel engine and the parameter values in the normal state.

$$
\delta=(y-x) / x
$$

$y$------ Thermal parameter values in fault condition

$x$------ Thermal parameter values in normal condition

The size of the $\delta$ value could be used to determine the sensitivity of different thermal parameters to the same fault of thermal power conversion. This was also the main basis for fault analysis. The fault sensitivity of thermal parameters was extracted based on the model simulation work process.

Simulation results of the cylinder pressure change curve and the size of fault sensitivity of thermal parameters was shown in Figure 2 and Figure 3. (Only listed the typical fault "oil spill failure")

The simulation results showed the sensitivity of the fault parameters under the oil spill failure, it showed the sensitivity of different thermal parameters to a fault. It could be used as a reference in the fault diagnosis. But in the simulation of diesel engine work process, no matter how accurate it is, you can't exactly get the same results as the actual conditions because of the complexity and discontinuity of the diesel engine work. The traditional fault threshold set for the diagnostic method based on simulation data wasn't accurate. Only when a large number of measured fault data can be applied to the fault threshold for the fault diagnosis. However, a large number of fault data was usually not available.

Although the simulation data can't get accurate operating parameters, but it can get the trend of the operating parameters. Whether the method of using the simulation model, obtaining the relationships of sensitivities of fault parameter to diagnose the fault was feasible, remains to be seen.

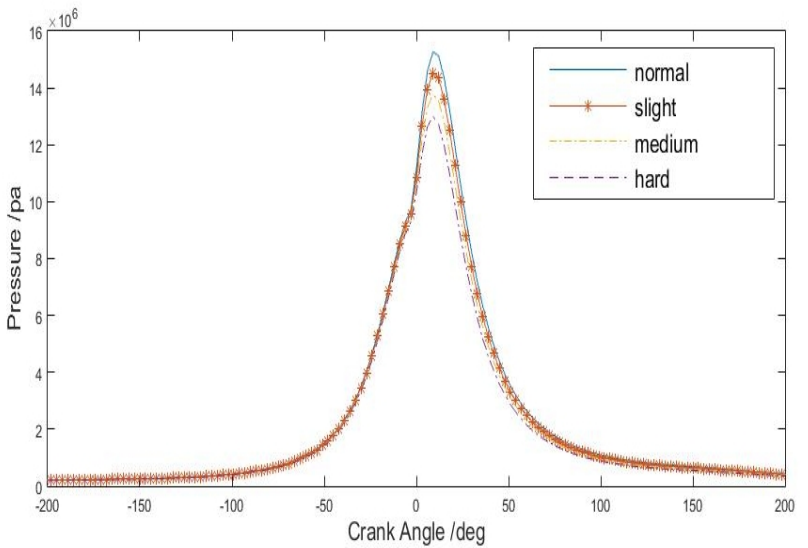

Figure 2. Different Degree of Fault Pressure Comparison

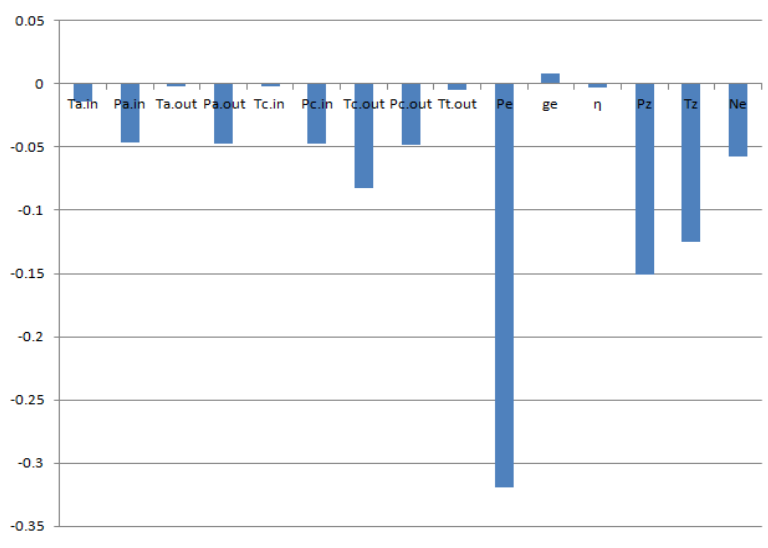

Figure 3. Sensitivity of Fault

Parameter 


\section{Establishment of Heat Characteristic Parameter Set and Fault Set}

In the diesel engine fault diagnosis, for some faults, such as "average effective pressure becomes low" is a set with unclear boundary. The use of traditional binary logic, the fault judgment by a certain range was unreasonable. It was more reasonable to identify faults by establishing the set of thermal parameters.

Considered two matrices:

1) Matrix of fault sensitivities of Thermal parameter ------ $X$

$$
X=\left[x_{1}, x_{2} \ldots, x_{m}\right]^{T}
$$

$\mathrm{m}$ was the number of faults, $x_{\mathrm{i}}=\left[x_{\mathrm{i} 1}, x_{\mathrm{i} 2} \ldots x_{\mathrm{in}}\right], \mathrm{n}$ was the number of thermal parameter sensitivity.

2) Matrix of faults ------ $Y$

$$
Y=\left[y_{1}, y_{2} \ldots y_{m}\right]^{T}
$$

$y_{i}$ was the names of faults.

It could be seen that there existed some relationships between the two matrices.

$$
X \cdot R=Y
$$

$R$ was a m-dimensional diagonal matrix. The elements $r_{i}$ in $R$ were n-dimensional permutation, and $r_{i}$ was the judgment matrix for diagnosing faults.

$$
R=\left\{\begin{array}{cccc}
r_{1} & 0 & \cdots & 0 \\
0 & r_{2} & \cdots & 0 \\
\vdots & \vdots & \cdots & \vdots \\
0 & 0 & \cdots & r_{m}
\end{array}\right\}
$$

Implementation was as follows. In the actual measurement, selected the main influence parameters determined in the simulation results. As for the simulation extraction and actually did not measure the thermal parameters, defined it as 0 . According to the actual measurement of the normal thermal parameters and fault parameters, calculated the fault sensitivity of thermal parameters. The fault sensitivityies of thermal parameters were arranged in the order of the simulation data, constituted the matrix of fault sensitivity of thermal parameters as $z=\left[z_{1}, z_{2} \ldots z_{n}\right]$. Calculated the sort matrix $\mu$ of matrix Z. The sort matrix was multiplied by the transposed matrix of the evaluation matrix to get the judgment matrix. All 0 rows and all 0 rows were removed, if the result was a unit matrix and the rank of the matrixit was equal to the number of elements, it was judged as a fault, output the corresponding element $y_{i}$ in the corresponding fault matrix $\mathrm{Y}$ corresponding to $r_{i}$. With this principle, we established the fault diagnosis system. The system flow char was shown in Figure 4.

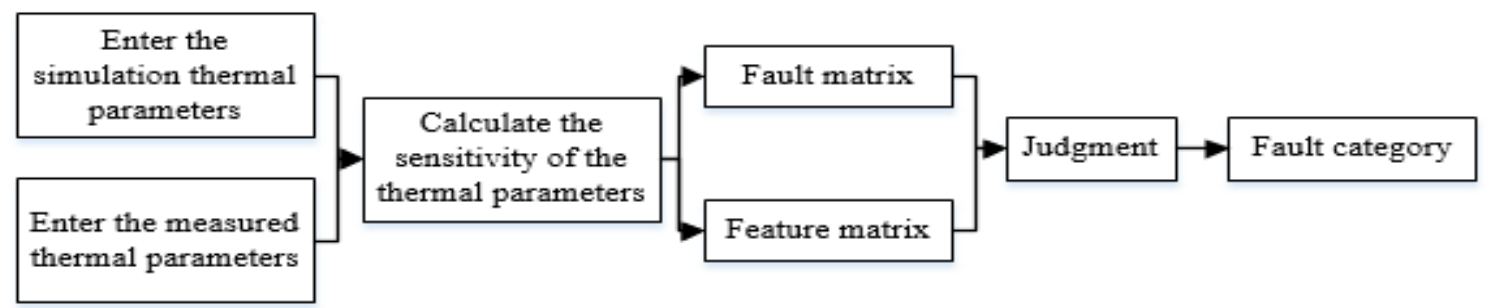

Figure 4. System Flow Char 


\section{Experimental verification}

The TBD234V6 diesel engine was selected for the test. The machine has the advantages of high reliability, low fuel consumption and wide power range. Main parameters were shown in Table 2.

Table 2. The Main Parameters of the Testing Machine

\begin{tabular}{|c|c|}
\hline Cylinder diameter & $128 \mathrm{~mm}$ \\
\hline Stroke & $140 \mathrm{~mm}$ \\
\hline Firing sequence & A1-B2-A3-B1-A2-B3 \\
\hline Rated power & $186 \mathrm{~kW}$ \\
\hline Calibration speed & $1500 \mathrm{r} / \mathrm{min}$ \\
\hline Compression ratio & 15 \\
\hline
\end{tabular}

Set the intercooler air side fouling fault as a validation test: Installed a butterfly valve on the intake line between the supercharger and the intercooler, controlled butterfly valve opening simulation intercooler air side fouling failure. Installed the pressure gauge before and after the intercooler to measure the gas pressure before and after the intercooler.

Selected the most sensitive parameters in the simulation results, adjusted the diesel engine to the rated conditions, then adjusted the butterfly valve opening, the measurement of sensitive thermal parameters results and normal conditions thermal parameters, the results showed in Table 3.

Table 3. Comparison of Measured Faults and Thermal Parameters of Normal Condition

\begin{tabular}{|c|c|c|c|}
\hline Parameter symbol & Unit & Normal Condition & Fault Condition \\
\hline$N e$ & $\mathrm{~kW}$ & 185.8 & 183.94 \\
\hline$P z$ & $\mathrm{Mpa}$ & 14.88 & 14.35 \\
\hline$T z$ & $\mathrm{~K}$ & 2021.59 & 2082.24 \\
\hline Pa.in & $\mathrm{kPa}$ & 228 & 225.7 \\
\hline Pa.out & $\mathrm{kPa}$ & 224.5 & 209 \\
\hline Tt.out & $\mathrm{K}$ & 680.5 & 708 \\
\hline Pc.in & $\mathrm{kPa}$ & 224 & 208 \\
\hline Pc.out & $\mathrm{kPa}$ & 182 & 175 \\
\hline
\end{tabular}

As the air flow was reduced, the excess air coefficient of the fuel was reduced, so the combustion efficiency was reduced, resulting in an effective power drop of the diesel engine. According to the formula, the fault sensitivity of thermal parameter was obtained, the results was shown in Figure 5. According to the simulation results of the fault sensitivity thermal parameters chart was shown in Figure 6.

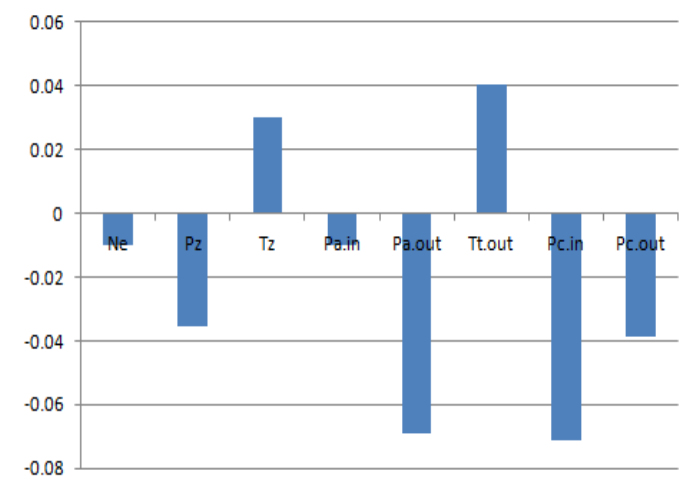

Figure 5.The Fault Sensitivity of

Thermal Parameters in Actual Condition

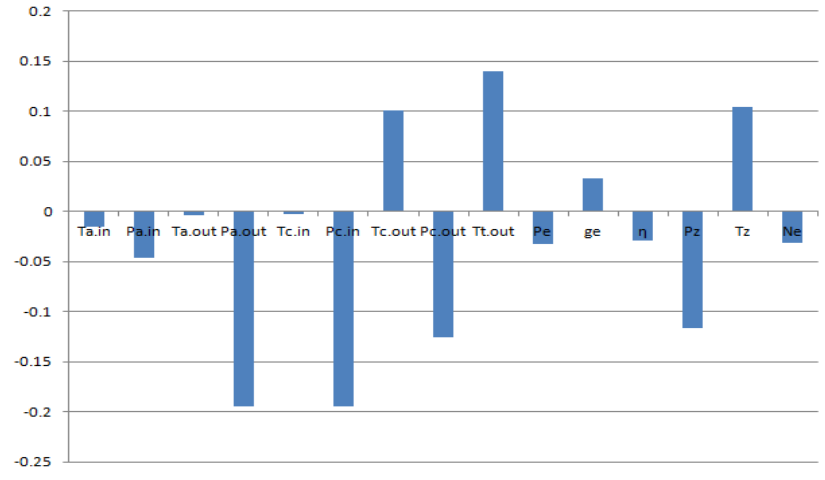

Figure 6.The Fault Sensitivity of Thermal Parameters in Simulation 
The sequence of the fault sensitivity of thermal parameters in the actual fault condition was:

$$
P_{\text {ein }}>P_{\text {aout }}>T_{\text {tout }}>P_{\text {eout }}>P_{z}>T_{z}>P_{\text {ain }}>N_{\text {o }}
$$

The sequence of the fault sensitivity of thermal parameters in the simulation results was:

$$
P_{\text {cin }}>P_{\text {anout }}>T_{\text {tout }}>P_{\text {cout }}>P_{z}>T_{z}>T_{\text {cout }}>P_{\text {ain }}>P_{u}>g_{u}>N_{u}>\eta>T_{\text {ain }}>T_{\text {a.out }}>T_{\text {cin }}
$$

According to the judgment principle described above, the judgment matrix was unit matrix, the rank of the matrix was 8 , and the number of elements was 8 . This results determined the occurence of intercooler air side fouling failure.

\section{Summary}

1) According to the fault simulation results, analyzed the thermal parameters and fault sensitivity of each fault, obtained the fault sensitivity of thermal parameters of each thermal power failure, got a set of associated diagnostic fault signs.

2)Proposed a fault diagnosis method based on simulation of fault signs set. Verified the feasibility of the method for calculating the sensitivity of thermal parameters.

\section{Acknowledgements}

The work is supported by National Natural Science Foundation of China (51409254).We are grateful for their financial supports.

\section{References}

[1] Rolf Isermann. Model-based Diagnosis of Diesel Engines[J]. MTZ worldwide,2017, 78 (4) :66-73.

[2] Chengtao Cai;Xiangyu Weng;Chuanbin Zhang. A novel approach for marine diesel engine fault diagnosis[J]. Cluster Computing.2017,20(2):1691-1702

[3] Odintsov Victor Ivanovich. Diagnosis of the technical state of diesel engines on the parameters of the operation process[J]. Vestnik of Astrakhan State Technical University. Series: Marine Engineering and Technologies.2012,1:123-128

[4] Hassan Moussa Nahim;Rafic Younes;Chadi Nohra;Mustapha Ouladsine. Complete modeling for systems of a marine diesel engine[J], Journal of Marine Science and Application.2015,14(3):93-104

[5] Nao Hu;Jianguo Yang;Yonghua Yu. Design and Implementation of Integrated Monitoring and Diagnosis System for Marine Diesel Engine[J]. Engineering Asset Management - Systems, Professional Practices and Certification.2015,647-659

[6] MD Cesare;C Pianese;S Falco;RD Leo;I Arsie. Estimation of the Engine Thermal State by in-Cylinder Pressure Measurement in Automotive Diesel Engines[J]. Sae Technical Papers,2015(1):F9-F14

[7]Gan Xie.Reaserach on Thermal Fault Simulation and Diagnosis for Marine Medium-speed Diesel Engine[D].JiMei University.2014 